Original scientific paper

\title{
SIMULATION OF MULTI-CRANE SINGLE AND DUAL CYCLING STRATEGIES IN A CONTAINER TERMINAL
}

\author{
Deniz, E. ; Tuncel, G. ${ }^{* *}$; Yalcinkaya, O.** \& Esmer, S. ${ }^{* * * * * * *}$ \\ * Dokuz Eylul University, The Graduate School of Natural and Applied Sciences, Izmir, Turkey \\ ${ }^{* *}$ Dokuz Eylul University, Department of Industrial Engineering, Izmir, Turkey \\ *** Iskenderun Technical University, Barbaros Hayrettin Naval Architecture and Maritime Faculty, \\ Hatay, Turkey \\ ***** Dokuz Eylul University, Maritime Faculty, Department of Logistics, Izmir, Turkey \\ E-Mail: elvandeniz@comu.edu.tr, gonca.tuncel@deu.edu.tr, ozgur.yalcinkaya@deu.edu.tr, \\ soner.esmer@deu.edu.tr
}

\begin{abstract}
Dual cycling is an operational strategy which can improve the efficiency of a quay crane (QC) and the land side operations of container ports by loading and unloading containers in the same cycle. Most of the research on the dual cycling strategy has focused on the modelling of single QC operations. MultiQC dual cycling reduces the operation time of a vessel involved in an operation. The aim of this study is to show how multi-QC single and dual cycling strategies can be modelled and analysed by simulation. Two simulation models are developed for a port container terminal to analyse the application results of single and dual cycling strategies used for vessel loading and unloading operations. Multi QC single cycling strategy is used in the first model while multi QC dual and single cycling strategy is used in the second model. The method is illustrated by a real-life case study. The findings of the simulation results show that the system performance can be improved by using the multi-QC dual cycling strategy.

(Received in February 2021, accepted in June 2021. This paper was with the authors 6 weeks for 1 revision.)
\end{abstract}

Key Words: Terminal Operations, Quay Crane, Dual Cycling, Simulation

\section{INTRODUCTION}

Port container terminals are international distribution systems which play an important role in international supply chains. With the rapid increase in container volume at ports, the increase in operational efficiency has become one of the most important issues for containers. Even though a new facility or new equipment such as quay crane (QC), rubber tired gantry (RTG) crane and truck can increase terminal efficiency, terminal decision makers are frequently reluctant to use this option because of the high investment cost [1]. QCs such as Ship-to-Shore gantry cranes are used to transport containers between vessels and the handling area or vice versa. QCs are one of the main bottlenecks in the efficient operation of container terminals. There are two types of QC strategies single cycling and dual cycling. In the single cycling strategy, QCs initiate the loading operations after all unloading operations have been completed for each bay. In the dual cycling strategy, it is possible to start with the unloading process and to load and unload the containers in the same bay simultaneously [2]. Unlike other options like investment, the dual cycling strategy in terminal operation is considered a low cost method to increase container terminals efficiency.

Dual cycling is a port terminal operation strategy in which the idle movements of QCs and empty trips of yard trucks are transformed into efficient ones. Fig. 1 shows a comparison of the sequence order between single and dual cycling strategies. It can be seen that, the dual cycling operation needs a total of 88 cycles whereas the single cycling operation needs 155 cycles to complete the same bay of the vessel. QC cycle means that is a QC spreader's round-trip between vessel and shore. 


\section{Single cycling sequence for unloading}

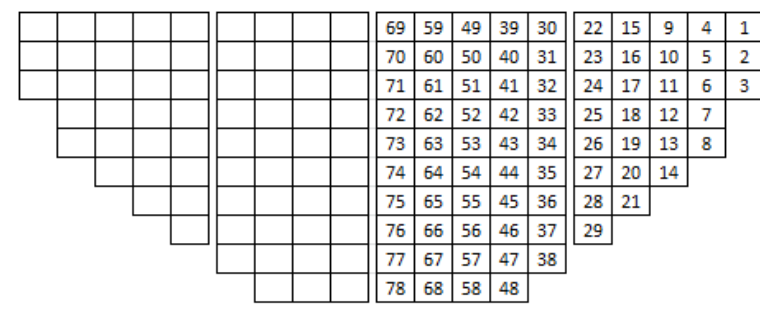

Single cycling sequence for loading

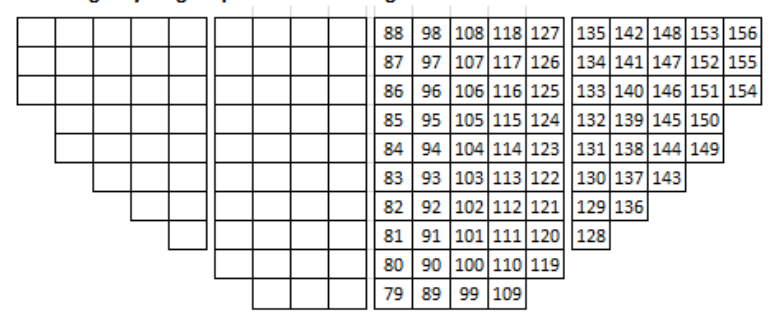

Dual cycling sequence for unloading

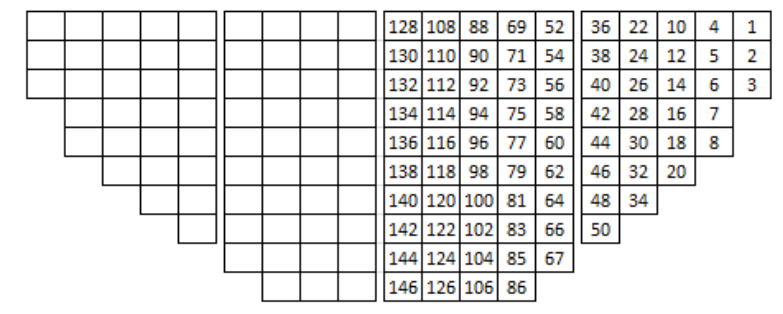

Dual cycling sequence for loading

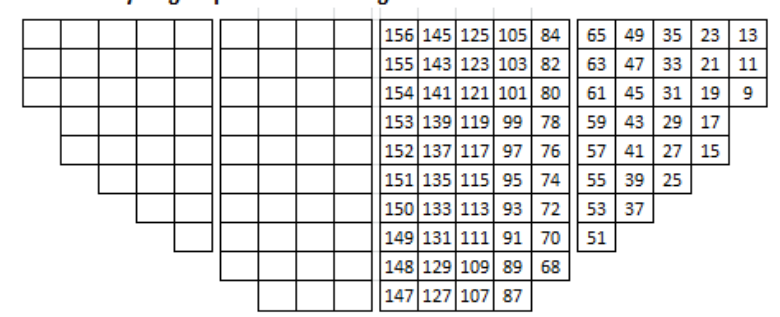

Figure 1: Comparison of the sequence order between single and dual cycling strategies.

Dual cycling strategies are also classified into two types: single QC and multiple QCs. In the single QC dual cycling, the operation is performed by a single QC within one bay, while in the multiple QCs dual cycling, the operation is performed by two or more QCs situated in separate bays. The most important benefit of dual cycling is the decreased number of QC cycles as well as increasing the efficiency of the vessel operations without the need for investment. The dual cycling strategy was first put forward by Goodchild and Daganzo [3], with the aim of minimizing the turnaround time of vessels in container terminals. The operation was carried out with an unloading and loading process which was described as a two-machine flow shop problem. Nguyen and Kim [4] studied double cycling operations of QCs, yard trucks, and yard cranes (YCs). An altered MIP model and a heuristic algorithm were suggested to minimize the empty movement time of yard trucks. Meisel and Wichmann [5] assumed that containers can be reshuffled on-board to improve the service process. Lee et al. [6] presented a model for the general QC dual cycling problem including hatch covers. Luo and Wu [7] proposed a new approach to determine the dispatching rules of AGVs and container storage locations, applying dual cycling strategy. In the following year, the dual cycling QC scheduling problem with hatches was considered to minimize the process cycles by Wang and Li [8]. Zhang et al. [9] used a MIP model for a two stage double cycling process to minimize the processing time of QC and YC. In the same year, Zeng et al. [10] developed a two-phase model for the QC dual cycling problem. The first model was the QC scheduling model, and the second one was an optimization model for outbound containers. $\mathrm{Ku}$ and Arthanari [1] presented a MIP model and hybrid heuristic approach decomposed into two parts: inter-stage sequencing and intra-stage sequencing. Zhang et al. [11] focused on overall handling efficiency and stability of terminal system. A closed queuing network was used to model terminal operations. Kamble et al. [12] identified a number of application barriers to the extensive use of double cycling in solving real-life problems. Recently, the study of He et al. [13] deals with QC scheduling of multiple hatches vessel taking into account the double-cycling strategy. They consider the balance between energy cost and operating efficiency.

Although the literature on single QC dual cycling is more common, the research on the multi-QC dual cycling is quite limited. Moreover, the implementation of dual cycling strategy in practice is also limited due to the need for some operational changes and lack of implementation tools. In this study, we propose a simulation modelling framework to model and analyse the effects of the single and dual cycling strategies on the overall system's performance. In previous studies in the literature, the advantages of dual cycling and single cycling methods were compared by operating them separately. Our paper differs from the 
literature in terms of the consideration of multiple QCs assigned to different bays where single and dual cycling are applied simultaneously to primarily evaluate the performance of QCs rather than trucks. The proposed methodology was illustrated with a loading and unloading plan of a real-life port where the dual cycling method cannot be applied in every bay of a container vessel due to some practical constraints such as crane dimensions, loading/unloading plans submitted by ship agencies, and container types. Within the scope of the problem addressed, the multiple QCs, single cycling and dual cycling methods were applied for the same loading and unloading plan. The problem under study includes three QCs that operate in different bays on a vessel simultaneously. One of the QCs operates with the single cycling method in one bay, and the other QCs operates with the dual cycling method in two different bays. The problem was modelled via the Arena simulation program and verified through the analysis of the implementation results. Our study revealed that practical extensions of the dual cycling problem that reflect the operating conditions of real-world container terminals are crucial to the effective design of terminal operations.

The remaining sections of this paper are organized as follows. The description of the case as well as the QC operation strategies are presented in Section 2. Simulation scenario is given in Section 3. The simulation model is developed, in Section 4, for the real-life case study introduced for illustration purposes. Simulation results are analysed in Section 5. Finally, the summary and concluding remarks are presented in Section 6.

\section{PROBLEM DESCRIPTION}

The ever-increasing container volumes brought along the need to improve the field and dock capacity of container terminals. Efficiency measurements are important for terminal operators as they are directly related to operating costs in terminals. While there are many ways to calculate efficiency, one of the most important efficiency measures is the efficient use of equipment used during container loading, unloading and storage. Equipment efficiency is a measure of the number of containers handled in one working hour for each machine. Another performance criterion is the utilization rate of the equipment. The QC is the most important equipment used in container terminals. The efficiency of loading and unloading operations can be increased by changing the working strategy of the crane. The two operational strategies are single cycling and dual cycling strategies.

\subsection{Single QC single cycling strategy}

Single cycling is an operational strategy where a QC performs its loading operations after the unloading operations of all containers in the vessel bay has been completed [1]. The handling process starts with the arrival of the vessel at the quay. The QC initially begins container unloading from the respective pre-planned bay. It loads the relevant container onto the truck that will bring it to the stock area at the pre-planned port access. The container is stacked by RTG in the storage area and the truck is released. The released truck returns to the reach of the QC while unloaded and this cycle continues until the unloading process is complete. After the unloading operation is completed, the containers to be loaded on the same vessel are once again loaded on the trucks by the RTGs in the relevant stock areas and the containers are brought to the QC reach in order and the truck is released. The QC loads the container on the vessel and completes the loading process as single cycle.

\subsection{Single QC dual cycling strategy}

Dual cycling is an operational strategy where a QC performs its loading and unloading operations in the same vessel-bay simultaneously. In other words, as a QC movement strategy, 
it is used to unload a container in the same cycle as the loading process. As noted by Goodchild and Daganzo [14], QC dual cycling strategy is regarded as a low-cost strategy used to increase the productivity of vessel operations. The benefit of QC dual cycling arises in that it improves the utilization of QC by converting empty crane movements into efficient ones. Additionally, the average utilization ratio of the RTGs used in stock areas also increases. QC dual cycling also reduces the empty trip rate of trucks in the field. The released truck does not return empty and heads to the nearest stock area where a loading operation is required. Figs. $2 \mathrm{a}$ and $2 \mathrm{~b}$ illustrate the comparison of the single QC single and dual cycling strategies.

(a) Single Cyling

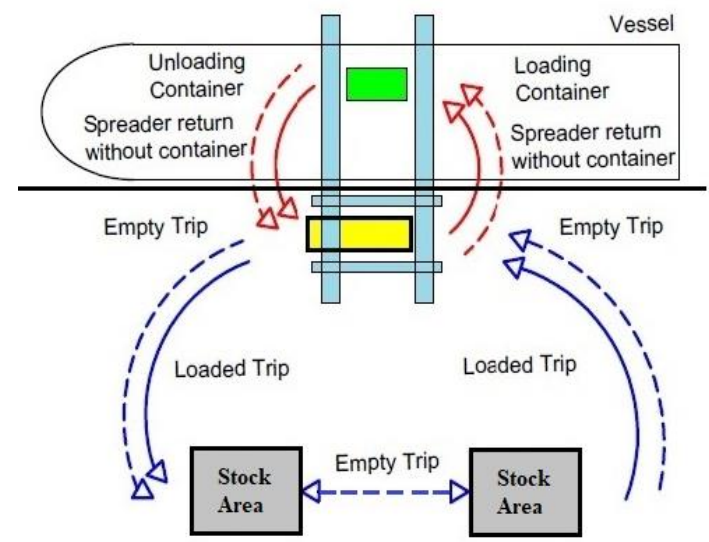

(b) Dual Cyling

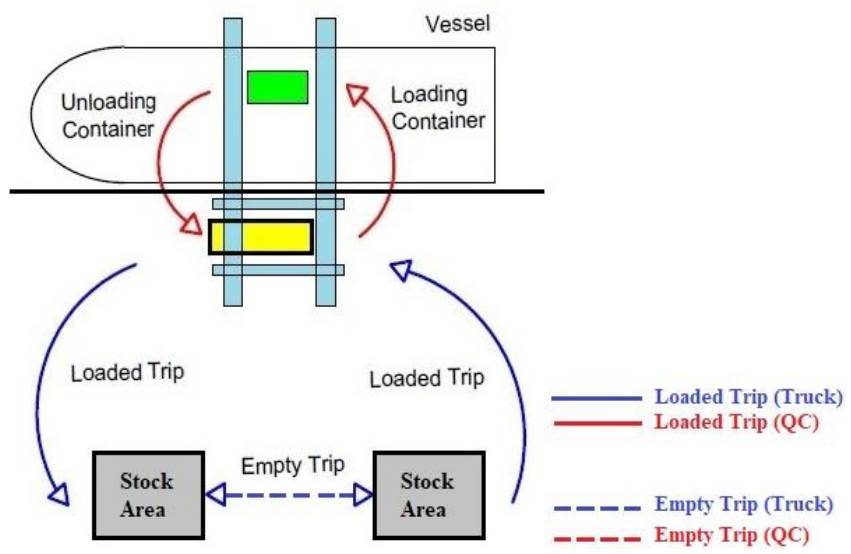

Figure 2: Comparison between single QC single cycling and dual cycling strategies.

\subsection{Multi-QC single and dual cycling strategy}

In case of using multiple QCs, the problem consists of two or more independent QCs working on different bays. QCs are one of the main bottlenecks in the efficient operation of container terminals. The planning of QC operations is an important factor that significantly affects the operating efficiency of container terminals [15]. For this reason, QC utilization rate is one of the most important criteria in measuring the performance of the operating systems of container terminals. The single cycling and dual cycling strategies can be used together in planning multiQC operations as shown in Fig. 3. The ultimate target of a vessel operation is to minimise the turnaround time of all QC activities on a vessel.

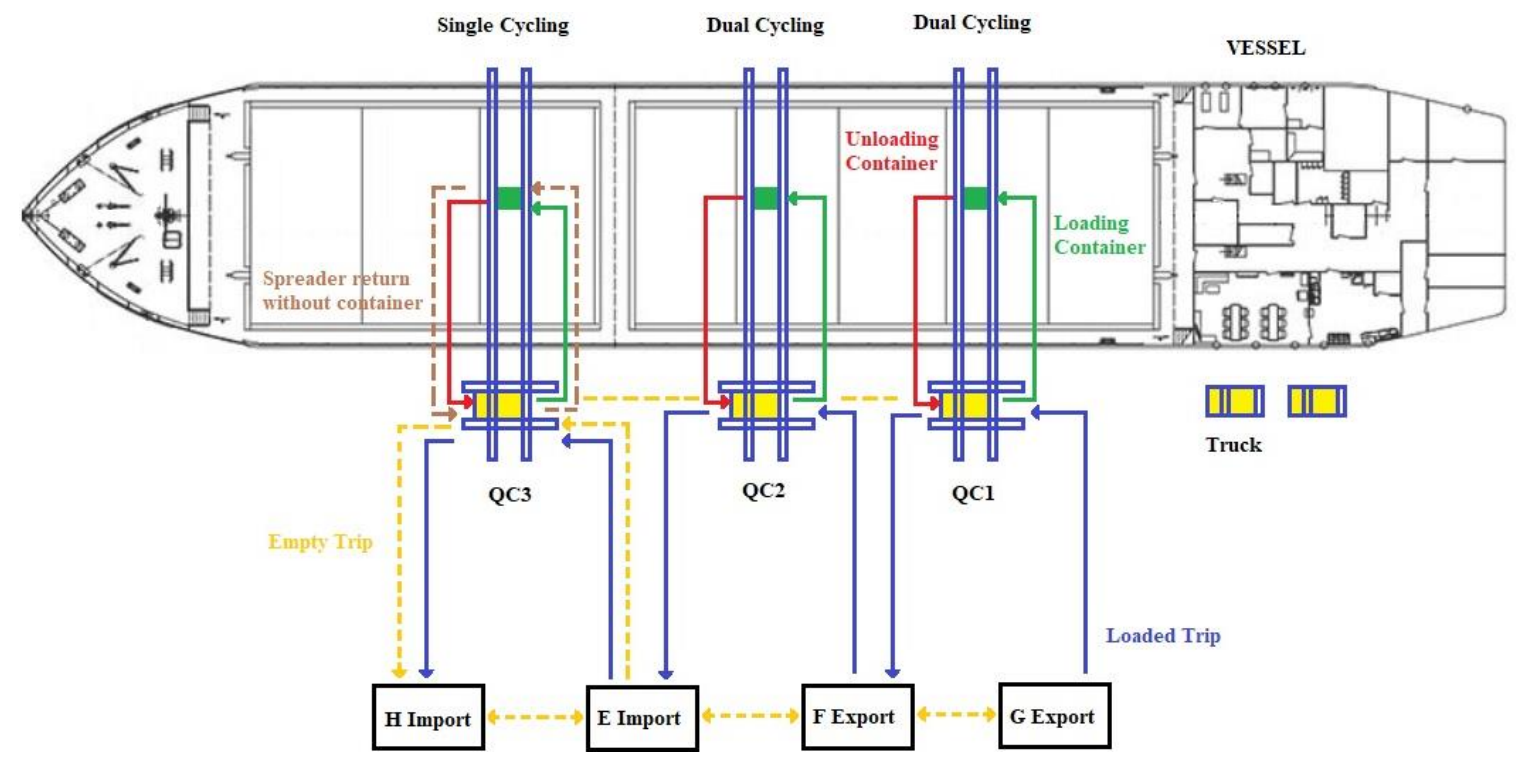

Figure 3: Multi-QC dual and single cycling strategies operated simultaneously. 


\section{SIMULATION SCENARIO}

The simulation study presented in this paper will be illustrated by a case study conducted in the port of Ambarl1 in Turkey. The port is located on the European Continent side of Istanbul. In addition to being the hinterland port of Istanbul and Marmara region, it can also be used as a transshipment hub for cargoes to the ports in the Black Sea countries. The port of Ambarli has three container terminals. One of them is Marport main terminal, which is considered in this study. Table I shows the list of resources at the Marport container terminal and the resources used in the handling operations discussed in this study.

Table I: Marport container terminal resources.

\begin{tabular}{|l|c|c|l|}
\hline \multicolumn{1}{|c|}{ Equipment } & $\begin{array}{c}\text { Total \# in } \\
\text { Marport }\end{array}$ & $\begin{array}{c}\text { Used in } \\
\text { simulation }\end{array}$ & \multicolumn{1}{|c|}{ Description } \\
\hline Berth & 7 & 1 & Berth 7 \\
Stock Area & 8 & 4 & E Import, F Export, G Export, H Import \\
Ship to Shore Gantry Crane & 10 & 3 & QC1, QC2, QC3 \\
Mobil Harbour Crane & 5 & 0 & \\
Rubber Tired Gantry & 41 & 8 & RTG ( 1-8 ) \\
Container Stacking Machine & 8 & 0 & \\
Empty Container Stacking Machine & 10 & 0 & \\
Truck & 102 & 21 & Truck (1-21 ) \\
\hline
\end{tabular}

Our simulation study is carried out for Berth 7 of the Marport terminal. The most important factors in choosing of Berth 7 were the depth of quay and the fact that the four most advanced quay cranes were located there. The handling plan of each vessel arriving at the port area was created in accordance with the requests of the agency that managed the vessel and, three bays of the selected vessel-bays (14, 34 and 62) were planned with the planning expert. There are several reasons to choose these bays. The dual cycling strategy is not applicable for loading and unloading operations of every vessel-bays. There are certain limitations in the implementation of planning operations. First of all, it is necessary to determine the suitable holding bays for dual cycling. There are many types of containers within the handling plan of the vessel, and these containers are required to be 40-foot for the implementation of the dual cycling strategy. Otherwise, the operating settings of the quay crane need to be changed by the operator every time the container type is changed. This situation causes an increase in time and cost in the operation. The bays 14 and 34 were selected from the bays suitable for the dual cycling method in these vessel-bays. Since the dual cycling operation plan cannot be performed in all bays of the vessel-bays in the operation planning phase, a single cycling strategy was also planned in the bay 62 while the work in the bays of 14 and 34 continued. Thus, a quay crane was assigned to each bay, the first crane was operated as a dual cycling in the bay 14, the second crane was operated as a dual cycling in the bay 34 and the third crane was operated as a single cycling in the bay 62 .

\section{THE SIMULATION MODEL}

Simulation is generally used in developing approaches to improve the performance of dynamic and complex systems such as intermodal terminal ports. We will present here two types of simulation models: multi-QC single cycling strategy and multi-QC dual and single cycling strategy using Arena simulation program. Our model provides estimates for reducing loading and unloading operation times for single and dual cycling operation strategies. 


\subsection{Developing the simulation model}

Two types of resources are defined in the simulation models. These are QC and RTG. There are three QCs and eight RTGs in the system. Four storage areas with two RTGs each are used for this process. QCs, such as Ship-to-Shore gantry cranes, are used to transport containers between vessels and the handling area or vice versa. RTGs are used for handling process in stock areas. Four storage areas with two RTGs each are used for this operation.

An import container generally follows the following flow:

- A QC unloads the import container from the vessel.

- The container is transported by a truck and stacked by a RTG in an appropriate storage area in the yard until delivered to an external transporter (see Fig. 4).

An export container generally follows the following flow:

- The export container arrives at the terminal via gate.

- It is transported with a truck and stacked by a RTG in an appropriate storage area in the yard until it is loaded onto a vessel.

- When it is time to be loaded, a truck transports the container to the berth.

- The QC loads the container in the bay planned in the vessel stack planning which specifies the location of the containers to be loaded (see Fig. 5).

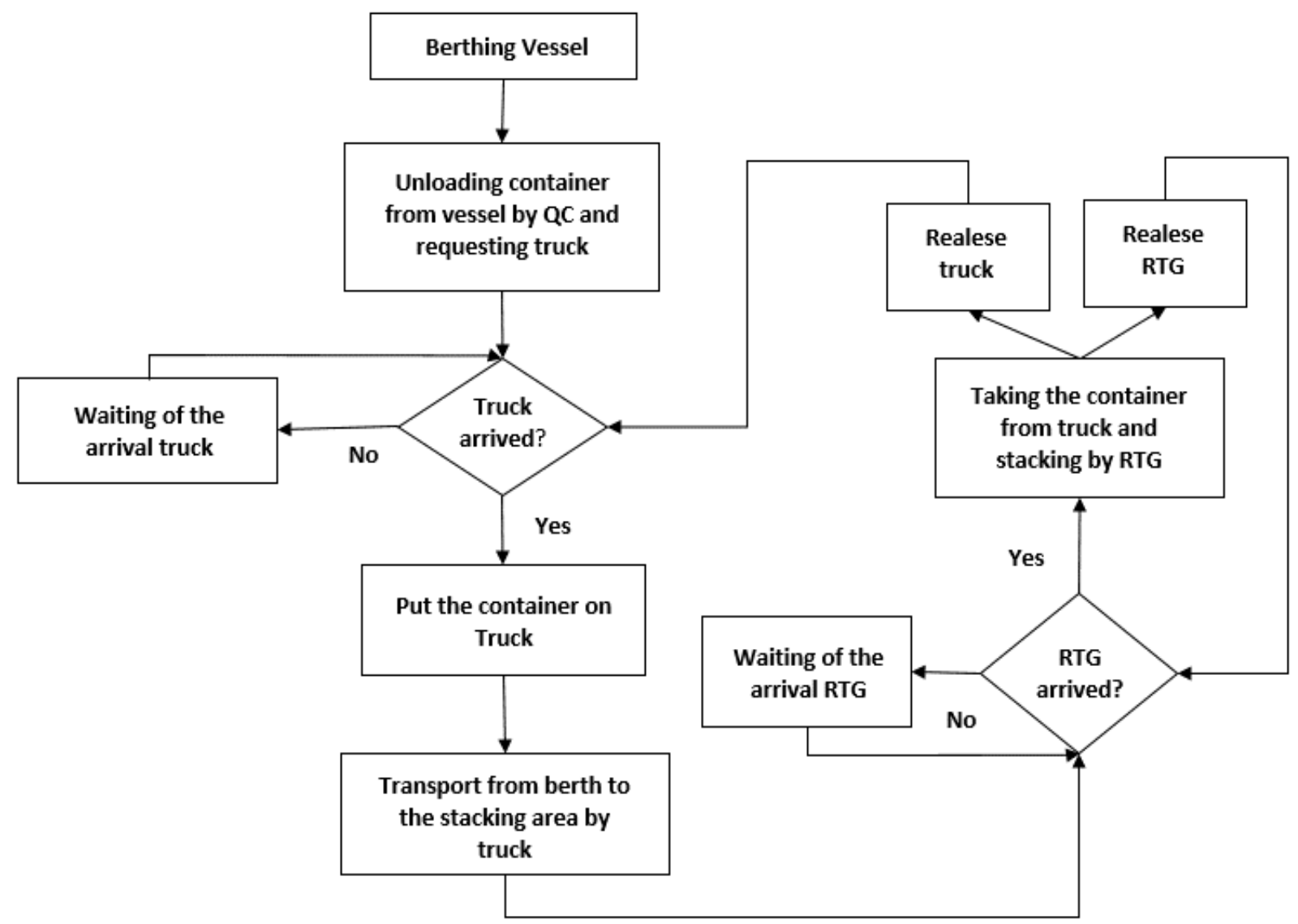

Figure 4: Flow diagram of unloading model. 


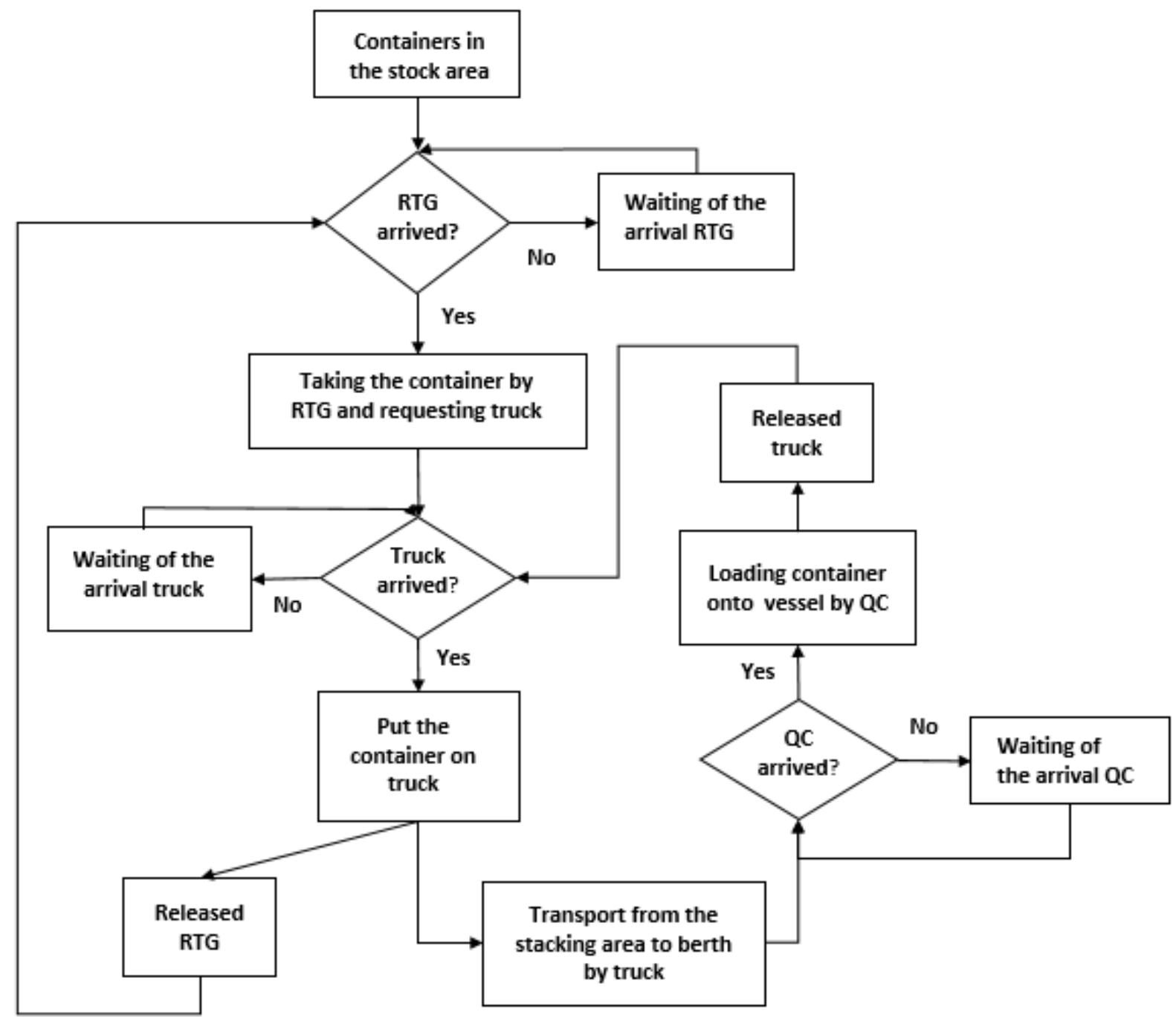

Figure 5: Flow diagram of loading model.

We constructed the simulation model based on the following assumptions related with container terminal under consideration:

- Each container can hold only one truck, one RTG and one QC.

- The data regarding the operation time of the QC and RTG are obtained based on observations.

- Only one type of transporters (truck) is defined in the models.

- The velocity of the trucks within the terminal is limited to $20 \mathrm{~km} / \mathrm{h}$. The truck's acceleration and deceleration process are ignored.

- All containers are 40' containers.

- All QCs and RTGs are of the same type and can only unload or load one container at a time.

- One QC cycle refers to the QC spreader's round-trip between vessel and shore.

- Three QC's are assigned for the vessel and each QC can be assigned to only one bay.

- Three QCs start unloading operation at the same time.

- QCs should not cross each other.

- We ignore equipment downtime. The port works at full capacity.

- Each truck can be assigned to more than one QC.

- All trucks are of the same type and can only transfer one container at a time.

- There are 21 trucks in the model. The first truck is requested for transporting. If the first truck is receiving service, the model makes the request sequentially until the last truck. This cycle is restarted if there are no empty trucks for transport. 
- It is assumed that all trucks can service to all QCs and RTGs. This will result in a decrease in empty truck utilization rate.

- Trucks in the field are directed to the nearest station where vehicles are requested.

The Marport distance matrix showing travel distances (meter) between all stations given in the transporter's system map is depicted in Table II.

Table II: Distance matrix of Marport.

\begin{tabular}{|c|c|c|c|c|c|c|c|}
\hline $\begin{array}{r}\text { TO } \\
\text { FROM }\end{array}$ & $\begin{array}{c}\text { Berth } \\
7 \_1\end{array}$ & $\begin{array}{c}\text { Berth } \\
7 \_2\end{array}$ & $\begin{array}{c}\text { Berth } \\
7 \_3\end{array}$ & $\begin{array}{c}\text { H import } \\
\text { Zone }\end{array}$ & $\begin{array}{c}\text { E import } \\
\text { Zone }\end{array}$ & $\begin{array}{c}\text { F export } \\
\text { Zone }\end{array}$ & $\begin{array}{c}\text { G export } \\
\text { Zone }\end{array}$ \\
\hline Berth 7_1 & - & 75 & 207 & 1575 & 970 & 410 & 365 \\
\hline Berth 7_2 & 75 & - & 105 & 1650 & 1045 & 485 & 440 \\
\hline Berth 7_3 & 207 & 105 & - & 1782 & 1177 & 617 & 572 \\
\hline H import Zone & 1715 & 1790 & 1922 & - & 995 & 1215 & 1360 \\
\hline E import Zone & 720 & 795 & 927 & 1610 & - & 220 & 365 \\
\hline F export Zone & 745 & 820 & 952 & 1750 & 1335 & - & 415 \\
\hline G export Zone & 355 & 430 & 562 & 1560 & 955 & 365 & - \\
\hline
\end{tabular}

\subsection{The simulation model inputs and validity-reliability analysis}

The input data of QCs and RTGs operation times are collected from the process of container loading and unloading services. The distributions of QCs and RTGs times are determined by using Input Analyzer tool of Arena. First, Input Analyzer was used to find the distributions of the crane times for each QC. The significance level of $5 \%(\alpha=0.05)$ was used for chi-squared goodness of fit tests for the crane times. According to the result of the input analysis, the appropriate distributions of the crane times of the first and second cranes were determined as Unif(1.52, 1.73) and Unif(1.92, 2.28). In addition, the appropriate distribution of the crane times of the third crane was the Unif(1.92,2.28) distribution. Secondly, Input Analyzer was used to find the distributions of the RTGs times for four stock areas. The significance level of $5 \%$ $(\alpha=0.05)$ was used for chi-squared goodness of fit tests for the RTGs times. According to the result of the input analysis, the most fit distribution of the RTGs times was $3.62+0.68 \times \operatorname{BETA}(1.42,1.4)$ distribution for Eimport, $3.63+0.65 \times \operatorname{BETA}(1.31,1.34)$ for Fexport, $3.63+0.66 \times \operatorname{BETA}(1.93,1.88)$ for Gexport and $3.62+0.67 \times \operatorname{BETA}(1.74,1.53)$ for Himport stock areas. These distributions were used in Arena program while creating the main simulation models.

Input data are transferred from Mport file to simulation model. Mport file consists of part no, order type, crane number, crane time, loading destinations and unloading destinations data. The model was replicated 10 times. The total operation time for each QC was compared with those represented in Table III.

Table III: Comparison of real and simulation results.

\begin{tabular}{|l|c|c|c|c|c|c|}
\cline { 2 - 8 } \multicolumn{1}{c|}{} & \multicolumn{2}{c|}{ QC 1 } & \multicolumn{2}{c|}{ QC 2 } & \multicolumn{2}{c|}{ QC 3 } \\
\hline First model & Real & Sim. & Real & Sim. & Real & Sim. \\
\hline Total operation time (min) & 330.90 & 327.18 & 330.04 & 326.91 & 197.23 & 199.86 \\
\hline Total movement (unit) & 156 & 156 & 155 & 155 & 92 & 92 \\
\hline Second model & Real & Sim. & Real & Sim. & Real & Sim. \\
\hline Total operation time (min) & 270.76 & 263.89 & 268.42 & 262.84 & 197.23 & 199.86 \\
\hline Total movement (unit) & 156 & 156 & 155 & 155 & 92 & 92 \\
\hline
\end{tabular}


As a result of each operation of the simulation models, total operation time was kept as a performance measure. For the validation of the models, the model outputs of the performance measures were compared with the real system values. As we have observed in Table III, the share of errors and deviations between two cases was less than $5 \%$. The container assignments were fulfilled at $100 \%$ match.

Table IV: Output analysis of the classical confidence interval relative to the mean of containers.

\begin{tabular}{|c|c|c|c|c|c|c|c|c|c|}
\hline \multirow[b]{2}{*}{ Description } & \multirow{2}{*}{\begin{tabular}{|c|}
$\begin{array}{c}\text { First } \\
\text { model }\end{array}$ \\
Single \\
cycling
\end{tabular}} & \multirow{2}{*}{$\begin{array}{c}\begin{array}{c}\text { Second } \\
\text { model }\end{array} \\
\begin{array}{c}\text { Dual + Single } \\
\text { cycling }\end{array} \\
\end{array}$} & \multirow[b]{2}{*}{ Diff. } & \multicolumn{3}{|c|}{ First model } & \multicolumn{3}{|c|}{ Second model } \\
\hline & & & & QC1 & QC2 & QC3 & QC1 & QC2 & QC3 \\
\hline Average (min) & 328.66 & 303.25 & 25.41 & 327.18 & 326.91 & 199.86 & 263.89 & 262.84 & 199.86 \\
\hline Minimum (min) & 326.74 & 297.85 & 28.89 & 323.54 & 322.24 & 195.24 & 260.75 & 258.47 & 195.24 \\
\hline Maximum (min) & 330.56 & 309.32 & 21.24 & 333.77 & 334.95 & 206.37 & 271.86 & 269.5 & 206.37 \\
\hline Standard deviation & 1.46 & 3.32 & & 3.27 & 4.54 & 4.13 & 3.37 & 4.07 & 4.13 \\
\hline$\% 95$ C.I. Half-Width & 1.04 & 2.37 & & 2.34 & 3.25 & 2.95 & 2.41 & 2.91 & 2.95 \\
\hline $\begin{array}{l}\text { Number of } \\
\text { observations }\end{array}$ & 10 & 10 & & 10 & 10 & 10 & 10 & 10 & 10 \\
\hline
\end{tabular}

We reconfirmed the validation of the model using the Output Analyzer. According to Table IV, a $95 \%$ confidence level was obtained using Arena Output Analyzer for the performance criterion. In addition, we conducted field visits and interviews with experts to evaluate the simulation results. It has been observed that the outputs of the real system and the simulation outputs are compatible. Hence, we concluded that the confidence interval is realistic.

\section{SIMULATION RESULTS AND DISCUSSION}

First, the simulation model was run with multi-QC single cycling strategy, then multi-QC dual and single cycling strategies was run. In order to evaluate the performance of the two strategies, the following performance parameters are taken into consideration; total operation time, number of containers waiting for each QC, RTG utilization rates, and number of trucks used for the operation. In the analysis, operation time refers to the amount of time required for the vessel operations of loading and unloading. The RTG utilization rates represent the RTG occupancy percentages. This indicator defines the percentage of the total time RTG by stacking for loading or unloading its containers. It indicates either efficient or inefficient utilization of the port equipment. We compare the obtained results in Table $\mathrm{V}$ in terms of the performance criteria. The results presented here are the average values of all simulation runs under distinct random seeds. We note that, different operational policies are simulated by the same set of random seeds to keep the container terminal environment the same for each strategy. We observed that the total operation time is 328.66 minutes in the first simulation model where multi-QC single cycling strategies are used. On the other hand, the total operation time is 303.25 minutes in the second simulation model where multi-QC dual and single cycling strategies are used together. The results show that the handling process of 403 containers with the single cycling strategy is performed with 25.41 minutes of extra time and a performance decrease of $7.7 \%$. Compared to the single cycling, we observed that the dual cycling strategy enables more efficient operation of the equipment used in the handling process, thereby reducing the vessel's operation time. In addition, the more efficient use of equipment will result in less investment in such costly equipment and will benefit businesses financially. 
Table V: Simulation results of the models.

\begin{tabular}{|l|c|c|c|c|}
\hline \multicolumn{1}{|c|}{ Description } & $\begin{array}{c}\text { Single } \\
\text { cycling }\end{array}$ & $\begin{array}{c}\text { Dual + Single } \\
\text { cycling }\end{array}$ & Diff. & Diff. \% \\
\hline Total Operation Time (min.) & 328.66 & 303.25 & 25.41 & $7.7 \%$ \\
Number of containers on the truck waiting QC1 & 2.57 & 0.94 & 1.63 & $63.4 \%$ \\
Number of containers on the truck waiting QC2 & 1.51 & 0.32 & 1.19 & $78.8 \%$ \\
Number of containers on the truck waiting QC3 & 0.08 & 0.08 & 0.00 & $0.0 \%$ \\
RTG in E import Utilization & $79.11 \%$ & $86.63 \%$ & -7.52 & $-9.5 \%$ \\
RTG in F export Utilization & $74.01 \%$ & $79.63 \%$ & -5.62 & $-7.6 \%$ \\
RTG in G export Utilization & $68.12 \%$ & $72.44 \%$ & -4.32 & $-6.3 \%$ \\
RTG in H import Utilization & $20.91 \%$ & $22.85 \%$ & -1.94 & $-9.3 \%$ \\
Number of trucks needed & 20.20 & 19.88 & 0.32 & $1.6 \%$ \\
\hline
\end{tabular}

Table VI gives the number of movements per hour of each crane, the bay number, the number of containers unloaded or loaded in each bay, and the operation times for the two models. QC movement per hour refers to the total number of movements of a QC in an hour. This is the other operational performance criterion of the QCs. Implementation results of two models are also compared with respect to the hourly performance of each QC. It can be seen that, the number of movement per hour of QC1 operated with single cycling is 28.6 and the number of movement per hour of QC1 operated with dual cycling is 35.5. According to these results, the efficiency of QC1 increases by $19.3 \%$ from the first model to the second model. Similarly, the number of movement per hour of QC2 operated with single cycling is 28.4 and the number of movement per hour of QC2 operated with dual cycling is 35.4. Here again, efficiency increases by $19.6 \%$ from the first model to the second one. Finally, the number of movement per hour of QC3 which was operated with only single cycling is 27.6 . In this case, when we analyse the run-time data of the simulation and the numbers of hourly movement of the QCs, we observed a performance increase in the QCs operating with the dual cycling.

Table VI: Hourly movement of the QCs for each model.

\begin{tabular}{|c|c|c|c|c|c|c|c|c|c|c|c|}
\hline \multirow{3}{*}{ Type } & \multirow{3}{*}{$\begin{array}{c}\text { QC } \\
\text { Number }\end{array}$} & \multicolumn{7}{|c|}{ Movement (pcs) } & \multirow{3}{*}{$\begin{array}{c}\text { Time } \\
\text { (minute) }\end{array}$} & \multirow{3}{*}{$\begin{array}{c}\text { Net } \\
\text { performance } \\
(\mathrm{MPH})\end{array}$} & \multirow{3}{*}{$\begin{array}{c}\text { Bay } \\
\text { number }\end{array}$} \\
\hline & & \multicolumn{2}{|c|}{ Single cycling } & \multicolumn{2}{|c|}{ Dual cycling } & \multicolumn{3}{|c|}{ Total } & & & \\
\hline & & Loading & Unloading & Loading & Unloading & Single & Dual & Total & & & \\
\hline \multirow{4}{*}{$\begin{array}{c}\text { Single } \\
\text { cycling }\end{array}$} & QC 1 & 78 & 78 & 0 & 0 & 156 & 0 & 156 & 327.18 & 28.6 & 14 \\
\hline & QC 2 & 77 & 78 & 0 & 0 & 155 & 0 & 155 & 326.91 & 28.4 & 34 \\
\hline & QC 3 & 48 & 44 & 0 & 0 & 92 & 0 & 92 & 199.86 & 27.6 & 62 \\
\hline & Total & 203 & 200 & 0 & $\mathbf{0}$ & 403 & 0 & 403 & & & \\
\hline \multirow{4}{*}{$\begin{array}{l}\text { Dual + } \\
\text { Single } \\
\text { cycling }\end{array}$} & QC 1 & 10 & 10 & 68 & 68 & 20 & 136 & 156 & 263.89 & 35.5 & 14 \\
\hline & QC 2 & 9 & 10 & 68 & 68 & 19 & 136 & 155 & 262.84 & 35.4 & 34 \\
\hline & QC 3 & 48 & 44 & 0 & 0 & 92 & 0 & 92 & 199.86 & 27.6 & 62 \\
\hline & Total & 67 & 64 & 136 & 136 & 131 & 272 & 403 & & & \\
\hline
\end{tabular}

Compared to the former model, where the QC1 and QC2 cranes were operated with the single cycling method, we observe a $19.5 \%$ increase in the average productivity of QC1 and QC2 when dual cycling method is applied. We can see that the average operation time for these two QCs was reduced by 63.68 minutes. There is no productivity change for the QC3 as it is operated with the single cycling method in both scenarios. On the other hand, as a result of the 
multi-QC dual and single cycling simulation model, in which all three cranes started to operate under the same conditions, the average operation time was reduced by 25.41 minutes and the average productivity of the cranes increased by $7.7 \%$. The reason why the weighted average efficiency value of the cranes is lower than expected is due to the equipment operating in the field operations. If we look at the efficiency of field equipment, we observe that the productivity rates of RTGs increased by average $8.2 \%$ on average, and the productivity increase rates of trucks were $1.6 \%$. This result has emerged because the productivity increase rate of cranes cannot be met by the productivity increase rates of RTG and trucks at the same rate. From the above results, a general conclusion is that the proposed multi QC strategy performs significantly better than the current operational strategy for all of the performance measures, as it considers the practical constraints with respect to the current state of the system. The results show QC operational strategies have a large impact on the performance measures of container terminals.

\section{CONCLUSION}

Simulation studies are used effectively to improve the performance of dynamic and complex systems such as container terminals. In addition to imitate port operations and provide predictions of outcomes and performances, simulation provides the user with an informative approximation of "what-if" scenarios to assist in supporting long-term strategic decisions or real-time decision-making. In this study, we considered a container terminal system in which loading and unloading operations are performed with a multi-QC dual cycling strategy. The main goal was to increase system efficiency and reduce operational time by analysing the operational processes in the container terminal. The simulation models were developed using the Arena simulation modelling software for two scenarios: multi-QC single cycling model and multi-QC dual and single cycling model. According to the implementation results, performance measures of QCs, RTGs, and transport vehicles were examined. For this purpose, the handling process of 40' containers, which is carried out by using three QCs from three separate bays at the container terminal was dealt with two different modelling approaches. The multi-QC single cycling strategy was used in the first model while, the multi-QC dual and single cycling strategy was used in the second model. The implementation results reveal the differences in time and performance between handling processes using two strategies. When a dual cycling strategy is applied during the handling process, the vessel's time on the quay is reduced and customer satisfaction and profitability increase due to reduced operating costs. Furthermore, container terminal equipment is used more efficiently because the dual cycling strategy increases the number of crane movements, percentage of RTGs utilizations and reduces the empty trips of trucks. For further research, we are planning to extend our model by a process optimization to minimize the total operation time and operational costs in the current model. Moreover, an optimization study can be conducted to determine the amount of RTGs and trucks that would minimize the total operation time and operational costs in the case of combined use of dual and single cycling strategies.

\section{REFERENCES}

[1] Ku, D.; Arthanari, T. S. (2016). On double cycling for container port productivity improvement, Annals of Operations Research, Vol. 243, No. 1-2, 55-70, doi:10.1007/s10479-014-1645-Z

[2] Zhang, H.; Kim, K. H. (2009). Maximizing the number of dual-cycle operations of quay cranes in container terminals, Computers \& Industrial Engineering, Vol. 56, No. 3, 979-992, doi:10.1016/ j.cie.2008.09.008

[3] Goodchild, A. V.; Daganzo, C. F. (2006). Double-cycling strategies for container ships and their effect on ship loading and unloading operations, Transportation Science, Vol. 40, No. 4, 473-483, doi: $10.1287 /$ trsc. 1060.0148 
[4] Nguyen, V. D.; Kim, K.-H. (2010). Minimizing empty trips of yard trucks in container terminals by dual cycle operations, Industrial Engineering and Management Systems, Vol. 9, No. 1, 28-40, doi:10.7232/iems.2010.9.1.028

[5] Meisel, F.; Wichmann, M. (2010). Container sequencing for quay cranes with internal reshuffles, OR Spectrum, Vol. 32, No. 3, 569-591, doi:10.1007/s00291-009-0191-6

[6] Lee, C.-Y.; Liu, M.; Chu, C. (2015). Optimal algorithm for the general quay crane double-cycling problem, Transportation Science, Vol. 49, No. 4, 957-967, doi:10.1287/trsc.2014.0563

[7] Luo, J.; Wu, Y. (2015). Modelling of dual-cycle strategy for container storage and vehicle scheduling problems at automated container terminals, Transportation Research Part E: Logistics and Transportation Review, Vol. 79, 49-64, doi:10.1016/j.tre.2015.03.006

[8] Wang, D.; Li, X. (2015). Quay crane scheduling with dual cycling, Engineering Optimization, Vol. 47, No. 10, 1343-1360, doi:10.1080/0305215X.2014.963070

[9] Zhang, R.; Jin, Z.; Ma, Y.; Luan, W. (2015). Optimization for two-stage double-cycle operations in container terminals, Computers \& Industrial Engineering, Vol. 83, 316-326, doi:10.1016/ j.cie.2015.02.007

[10] Zeng, Q.; Diabat, A.; Zhang, Q. (2015). A simulation optimization approach for solving the dualcycling problem in container terminals, Maritime Policy \& Management, Vol. 42, No. 8, 806-826, doi:10.1080/03088839.2015.1043362

[11] Zhang, X.; Zeng, Q.; Sheu, J.-B. (2019). Modeling the productivity and stability of a terminal operation system with quay crane double cycling, Transportation Research Part E: Logistics and Transportation Review, Vol. 122, 181-197, doi:10.1016/j.tre.2018.12.003

[12] Kamble, S. S.; Gunasekaran, A.; Raut, R. D. (2019). Analysing the implementation barriers of dual cycling in port container terminal using interpretive structural modelling - Indian context, International Journal of Logistics Research and Applications, Vol. 22, No. 2, 119-137, doi:10.1080/13675567.2018.1492531

[13] He, J.; Yu, H.; Tan, C.; Yan, W.; Jiang, C. (2020). Quay crane scheduling for multiple hatches vessel considering double-cycling strategy, Industrial Management \& Data Systems, Vol. 120, No. 2, 253-264, doi:10.1108/IMDS-03-2019-0191

[14] Goodchild, A. V.; Daganzo, C. F. (2007). Crane double cycling in container ports: Planning methods and evaluation, Transportation Research Part B: Methodological, Vol. 41, No. 8, 875891, doi:10.1016/j.trb.2007.02.006

[15] Ku, D. (2015). Research on Marine Terminal Logistics: Crane Double Cycling Models, Ph.D. Dissertation, The University of Auckland, Auckland 